\title{
Energy balance and metabolic rate in preterm infants fed with standard and high-energy formulas
}

\author{
BY O. G. BROOKE \\ Department of Child Health, St George's Hospital Medical School, \\ Cranmer Terrace, London $S W_{I 7}$
}

(Received 13 August 1979 - Accepted 3. January 1980)

\begin{abstract}
I. Energy balances were performed on sixteen low birth weight preterm infants over 7-10 d periods on a standard low-solute infant formula $(2600 \mathrm{~kJ} / \mathrm{l})$, and on four high-energy formulas, providing different energy densities up to $3760 \mathrm{~kJ} / \mathrm{l}$. In two of the high-energy formulas the additional fat energy was provided by peanut oil, and in the other two by medium chain triglycerides (MCT). Anthropometric measurements and metabolic rate (MR) determinations were made during the balance periods.

2. Mean energy retention on the standard formula was $66 \%$ of the intake and declined to below $50 \%$ on the two feeds providing the highest energy. Extensive energy balance data on the standard formula are available for reference.

3. Net absorption of dietary energy increased on all the high-energy formulas, rising from $362 \mathrm{~kJ} / \mathrm{kg}$ per $\mathrm{d}$ on the standard formula to $453 \mathrm{~kJ} / \mathrm{kg}$ per $\mathrm{d}$ on the highest energy-formula $(P<0.001)$. There was no advantage in using MCT.

4. Net absorption of dietary energy improved with advancing maturity, irrespective of the formula.

5. In spite of the increased dietary energy retention, there was no increase in growth rate during periods of feeding with the high-energy formulas.

6. Fasting and postprandial MR increased by 10.4 and $12.8 \%$ respectively on the highest energy feeds.

7. It is concluded that, at least in the short term, this type of high-energy feeding increases MR at the expense of growth and thus is probably of no advantage to the infant.
\end{abstract}

Energy balance is an important aspect of the nutrition of immature infants. Their energy losses are high, their requirement for growth is considerable (Brooke et al. 1979), and they have various disadvantages in relation to the digestion and absorption of dietary energy. Poor energy retention may also lead to negative nitrogen balance, as endogenous proteins are converted to glucose. The difficulties of getting adequate food energy into small immature neonates by mouth, mainly due to their intolerance of large feed volumes, has led to various attempts at improving their nutrition and weight gain by the use of highenergy formulas (Morales et al. 1950; Hardy \& Goldstein, I95I ; Combes \& Pratt, I96I; Snyderman \& Holt, I96I; Falkner et al. 1962; Keitel \& Chu, 1965; Brooke \& Alvear, I976; Wenner, 1977).

Although many neonatal units now make extensive use of parenteral nutrition in very small infants, there are hazards to intravenous feeding (Committee on Nutrition: Parenteral Feeding, 1972; Postuma \& Trevenen, 1979), and it cannot usually be maintained for long periods without considerable technical difficulty. Thus the use of suitably adapted milk formulas is attractive. In spite of the recent enthusiasm for human breast milk in infant feeding, there are sound reasons for believing that it may not be ideal for the preterm infant (Fomon et al. 1977), and formulas based on modified cow's milk are widely used and have formed the basis for all high-energy formulas reported in the literature.

Early investigators relied mainly on increasing the concentration of whole-milk formulas to raise the energy intake, with the attendant problems of high protein and mineral intake and the risk of plasma hyperosmolality. It is the practice in some neonatal units to enrich their infant formulas with an additional source of energy, such as maize oil (Gregory, 1972) and, if it could be shown to be useful, this approach would avoid the problems of 
Table I. Clinical details of sixteen low-birth-weight infants

\begin{tabular}{|c|c|c|c|c|c|}
\hline Infant & Sex & $\begin{array}{l}\text { Birth wt } \\
\text { (g) }\end{array}$ & $\begin{array}{l}\text { Gestation } \\
\text { (weeks) }\end{array}$ & $\begin{array}{c}\text { Age at } \\
\text { start of studies } \\
\text { (d) }\end{array}$ & $\begin{array}{c}\text { Wt at } \\
\text { start of studies } \\
\text { (g) }\end{array}$ \\
\hline MI & $q$ & 1325 & 31 & 17 & 1440 \\
\hline JW & $\vec{a}$ & 1010 & 29 & 23 & 1206 \\
\hline PA & q & 1000 & 30 & 25 & 1304 \\
\hline HA & $q$ & 1150 & 30 & 17 & 1417 \\
\hline PM & $\sigma^{*}$ & 1375 & 33 & I2 & 1446 \\
\hline FB & $\vec{\sigma}$ & 1280 & 35 & 10 & 1320 \\
\hline AS & 6 & 1510 & $3 \mathrm{I}$ & 10 & I 518 \\
\hline JR & $\vec{\sigma}$ & 1460 & 30 & 15 & 1517 \\
\hline MH & $\vec{a}$ & 1220 & 29 & 21 & 1390 \\
\hline $\mathbf{L F}$ & 우 & 1350 & 30 & 24 & 1494 \\
\hline JS & $q$ & 1100 & 29 & 16 & 1200 \\
\hline JK & $\sigma^{2}$ & 990 & 32 & 30 & 1080 \\
\hline PF & के & I195 & 33 & 20 & I 275 \\
\hline AL & $q$ & 1080 & 29 & 18 & 1170 \\
\hline LL & $a$ & 1200 & 31 & 15 & 1290 \\
\hline SW & $\hat{o}^{*}$ & 1210 & 32 & 16 & 1250 \\
\hline Mean & & 1216 & $3 I$ & 18 & 1332 \\
\hline
\end{tabular}

hyperosmolality while improving energy balance. It has, however, never been properly investigated, and the practice of empirically adding energy as fat (or carbohydrate) without verifying that it will result in improved energy balance, and without attention to the vital question of the protein:energy ratio, is likely to lead to trouble. The purpose of this investigation was to examine the effect of dietary energy supplements on energy balance in immature infants, and in particular to see whether supplementary medium-chain triglycerides (MCT) were of any value.

\section{EXPERIMENTAL}

\section{Patients and methods}

Sixteen infants were studied. All were very small at birth and were in the neonatal unit for several weeks before discharge. This enabled a number of balances to be performed on each infant while on the various formulas. Some clinical details of the infants are given in Table I. No attempt was made to evaluate light-for-dates infants separately since the numbers were too small. None of the infants was ill during the balances.

Serial anthropometry. This was done on all infants as follows: body-weight, daily to the nearest $10 \mathrm{~g}$ on a Marsden beam balance; crown-heel, crown-rump and rump-heel lengths, weekly to the last completed I mm on a Harpenden stadiometer; occipito-frontal head circumference, daily to the last completed I mm, using disposable paper tape; midupper arm circumference, twice weekly to the last completed I mm; maximum calf circumference, twice weekly to the last completed I $\mathrm{mm}$; triceps and subscapular skinfold thickness, twice weekly to the last completed $0 \cdot I \mathrm{~mm}$ after the caliper had ceased contracting on the fold, using a Harpenden caliper.

Feeds. Balances were not begun until the infant had been established on full-strength low-solute cow's milk-based formula $(2600 \mathrm{~kJ} / \mathrm{l})$ for at least I week at an intake of at least $180 \mathrm{ml} / \mathrm{kg}$ daily. None of the infants in this study was fed breast-milk (the mothers either did not wish to breast feed, or had given up expressing milk by the time the balances were begun). The standard formula in use in the Unit at the time was a 'filled' milk whose composition is given in Table 2. 
Table 2. Approximate composition of the standard and high-energy formulas (per l prepared feed)

\begin{tabular}{lrrrrr} 
Formula ... & Standard & \multicolumn{1}{c}{} & \multicolumn{1}{c}{} & \multicolumn{1}{c}{3} & 4 \\
Total fat (g) & 31 & 44 & 44 & 51 & 51 \\
C8-C10:0 (mg/g total fat) & 5 & 4 & 300 & 3 & 390 \\
C16:0 (mg/g total fat) & 320 & 240 & 220 & 220 & 190 \\
C18:0 (mg/g total fat) & 60 & 60 & 40 & 60 & 40 \\
C18:I (mg/g total fat) & 320 & 400 & 220 & 430 & 190 \\
C18:2 (mg/g total fat) & 150 & 170 & 110 & 180 & 90 \\
Protein (g) & 18 & 17 & 17 & 17 & 17 \\
Protein energy (\%) & 12 & $9 \cdot 1$ & $9 \cdot 2$ & $7 \cdot 6$ & $7 \cdot 7$ \\
CHO (g) & 70 & 67 & 67 & 95 & 95 \\
Minerals (g) & 4 & 4 & 4 & 4 & 4 \\
Energy (kJ) & 2600 & 3020 & 2980 & 3760 & 3710 \\
Osmolality (mOsm/kg) & 300 & 385 & 405 & 461 & 506
\end{tabular}

Infants were tube-fed by gavage or bottle-fed as appropriate, at 2-, 3- or 4-hourly intervals, according to their size and maturity. All received supplementary vitamins $\mathrm{A}, \mathrm{C}$ and D. Feed volumes were kept as near as possible to $200 \mathrm{ml} / \mathrm{kg}$ daily during the balances.

Energy supplements. The high-energy feeds were made by adding nutrient emulsions to the standard formula. Four different emulsions were used: (1) $35 \mathrm{~g}$ peanut oil; (2) $35 \mathrm{~g} \mathrm{MCT}$ (Cow and Gate); (3) 28.5 g peanut oil and $40 \mathrm{~g}$ sucrose; (4) $28.5 \mathrm{~g} \mathrm{MCT}$ and $40 \mathrm{~g}$ sucrose; all were emulsified with acacia and made up to $100 \mathrm{ml}$ with water. The emulsions were shaken well and added to the standard formula just before the feeds in the following amounts: formula I: emulsion I, $42 \mathrm{ml} / 1$ milk; formula 2 : emulsion 2, $42 \mathrm{ml} / 1 \mathrm{milk}$ (formulas I and 2 had a total energy of approximately $3000 \mathrm{~kJ} / 1$ (750 kcal)); formula 3 : emulsion 3, $83 \mathrm{ml} / 1$ milk; formula 4 : emulsion $4,83 \mathrm{ml} / 1$ milk (formulas 3 and 4 had a total energy of approximately $3790 \mathrm{~kJ} / 1$ (900 kcal)). Table 2 gives some details of the composition and measured osmolality of the four formulas, as fed to the infants.

Rotation of feeds. The infants were fed on the various formulas according to a prearranged plan, the same infant acting as his own control. The limited time available made it impossible for any infant to receive all four high-energy feeds. Because of the likely improvement in gut function with increasing maturity, the order in which the feeds were given was rotated. Every infant had one balance period on the standard formula, which was given first in six infants, second in five infants and third in five infants. Formula I was given to nine infants, formula 2 to seven infants, formula 3 to nine infants, and formula 4 to six infants. Each formula was given for 7-10 d, but during the first $3 \mathrm{~d}$ the high-energy formulas were introduced in graduated strengths. Infants were re-established on the standard formula before discharge.

Energy balances. Balances were continuous. Total energy in formulas and faeces was measured by bomb calorimetry (Miller \& Payne, 1965). Intake was measured by volume. Vomits were collected on weighed absorbent pads, their quantity assessed by reweighing, and subtracted from the intake. All stools were collected in weighed rayon napkin liners, promptly frozen at $-24^{\circ}$ in sealed plastic bags, weighed, freeze-dried, homogenized in daily aggregates, and analysed by bomb calorimetry. Faecal energy losses were then subtracted from the intake to give energy balance, which was obtained for the entire period on each formula. The beginning and end of balances were marked with carmine.

Energy expenditure. To try to determine whether the high-energy formulas caused increased energy expenditure, resting metabolic rate (MR) and postprandial MR were measured towards the end of each balance period by open-circuit indirect calorimetry, using a Kipp diaferometer. For these determinations the expired air was collected at 
known flow rate using either a ventilated acrylic metabolic chamber or a head-box (Brooke et al. 1979). During each determination, 5 min measurements of $M R$ were made in the resting pre-prandial state and then at $15 \mathrm{~min}$ intervals for $60 \mathrm{~min}$ after the feed had been given. The thermic effect of the feeds was measured from the area under the curve. The diaferometer was calibrated by burning alcohol. Measurements of pre- and postprandial metabolism were made in all infants.

Other measurements. Because of the ketogenic effect of MCT (Schon et al. 1959) and the relatively high osmolality of some of the feeds, it was thought advisable to check blood gases and plasma osmolality during each balance period. Blood samples for these determinations were taken by heel stab at the same time as routine weekly haemoglobin estimations, thus avoiding additional blood sampling.

Ethical aspects. The studies were approved by the Hospital Ethical Committee. Permission for the studies was obtained from all mothers.

Statistical analysis. All statistical comparisons between values on standard and highenergy formulas were made by analysis of variance using a regression method.

\section{RESULTS \\ Energy balances}

Table 3 gives the results for the energy balances in all the infants on the various formulas. While faecal energy increased progressively on the high-energy formulas, so did net energy retention; thus the proportion of the energy intake retained declined at higher levels of dietary energy, but the absolute amount of food energy retained increased.

The standard formula was compared with the other formulas by analysis of variance, each infant serving as his own control (Table 4). Although there was no significant difference in net energy retention between the standard formula and either of the 'low level' additives (formulas I and 2), when the data for these two formulas were combined, there was significantly greater energy retention than on the standard formula $(P<0.05)$. There was no significant difference in energy retention between the peanut oil and the MCT formulas at either level of energy intake. Energy retention was significantly greater on formula 3 than on formula i $(t 3.5, P<0.01)$, and on formula 4 than on formula $2\left(t 4^{\circ} 0\right.$, $P<0.00 I)$. Fig. I shows the relationship between maturation and energy balance on standard formula, there being a significant improvement in net absorption with increasing post-conceptional age. A similar trend was seen on the high-energy formulas, but the numbers were too small to establish its significance.

There was considerable individual variation in energy balances from day to day. This appears to be a biological phenomenon, not a collection artifact, since all infants passed more than one stool daily, the average number of defaecations being $3 \cdot 2 / \mathrm{d}$. The original energy balance values are given in the Appendix, both to show the extent of this variation and also as a source of reference, since such values are not readily available.

\section{Growth}

Table 5 shows the rates of growth in the various physical measurements during the balance periods on each formula. It was not thought necessary to use a grid system (Keitel et al. I965) for this comparison because the feed rotation ensured that the growth measurements covered a similar post-conceptional age period. The growth rates were compared by analysis of variance. There were no significant differences in growth rates on any of the formulas except in crown-heel length on formula 2 . Infants on this formula had significantly poorer linear growth than they did on the standard formula $(P<0.001)$. 
Table 3. Energy balance values on the standard formula and the high-energy formulas*

(Mean values and standard deviations, no. of infants in parentheses)

\begin{tabular}{|c|c|c|c|c|c|c|c|c|c|c|}
\hline \multirow[t]{2}{*}{ Formula $\ldots$} & \multicolumn{2}{|c|}{ Standard (I6) } & \multicolumn{2}{|c|}{ I (9) } & \multicolumn{2}{|c|}{$2(7)$} & \multicolumn{2}{|c|}{$3(9)$} & \multicolumn{2}{|c|}{$4(6)$} \\
\hline & Mean & SD & Mean & SD & Mean & SD & Mean & SD & Mean & SD \\
\hline Intake ( $\mathrm{kJ} / \mathrm{kg}$ body-wt) & 554 & 44 & 659 & 34 & 662 & I6 & 767 & 39 & 780 & 24 \\
\hline $\begin{array}{l}\text { Faecal loss } \\
(\mathrm{kJ} / \mathrm{kg} \text { body-wt) }\end{array}$ & 192 & 52 & 253 & 75 & 256 & 61 & 309 & 94 & 320 & 96 \\
\hline $\begin{array}{l}\text { Energy retention } \\
(\mathrm{kJ} / \mathrm{kg} \text { body-wt) }\end{array}$ & 362 & 56 & 406 & 82 & 402 & 74 & 453 & 102 & 460 & 96 \\
\hline $\begin{array}{l}\text { Energy retention } \\
\text { (\% energy intake) }\end{array}$ & 66 & 9 & $6 I$ & II & $6 I$ & 9 & 59 & 12 & 58 & 12 \\
\hline
\end{tabular}

Table 4. Net energy retention in sixteen low-birth-weight infants on standard and high-energy formulas $\dagger$

\begin{tabular}{|c|c|c|}
\hline & $\begin{array}{l}\text { Proportion of energy } \\
\text { retained }\end{array}$ & $\begin{array}{l}\text { Net energy retention } \\
\text { (digestible energy) }\end{array}$ \\
\hline $\begin{array}{l}\text { Formula I } v \text {. standard formula } \\
\text { Formula } 2 v \text {. standard formula } \\
\text { Formula } 3 v \text {. standard formula } \\
\text { Formula } 4 \text { v. standard formula }\end{array}$ & $\begin{array}{l}-0.046 \mathrm{NS} \\
-0.06 \mathrm{I} \mathrm{NS} \\
-0.098 \mathrm{NS} \\
-0.106 \mathrm{NS}\end{array}$ & $\begin{array}{l}+0.083 \mathrm{NS} \\
+0.105 \mathrm{NS} \\
+0.220^{* * *} \\
+0.267^{* * *}\end{array}$ \\
\hline
\end{tabular}

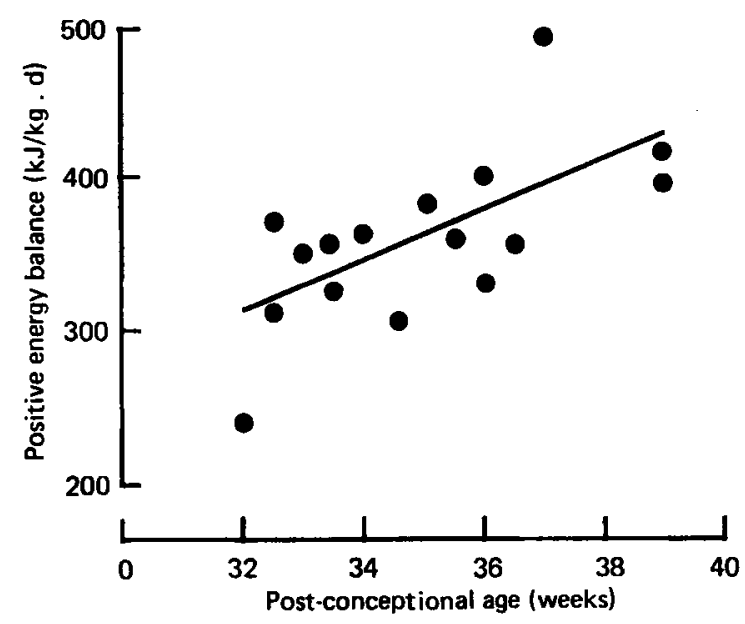

Fig. 1. Correlation between daily energy balance ( $\mathrm{kJ} / \mathrm{kg}$ body-weight) and maturity in sixteen low-birth-weight infants on a standard formula (for details, see p. 14 and Table 2). 
Table 5. Rates of physical growth during the various balance periods

(Mean weekly increments and standard deviations; no. of infants in parentheses)

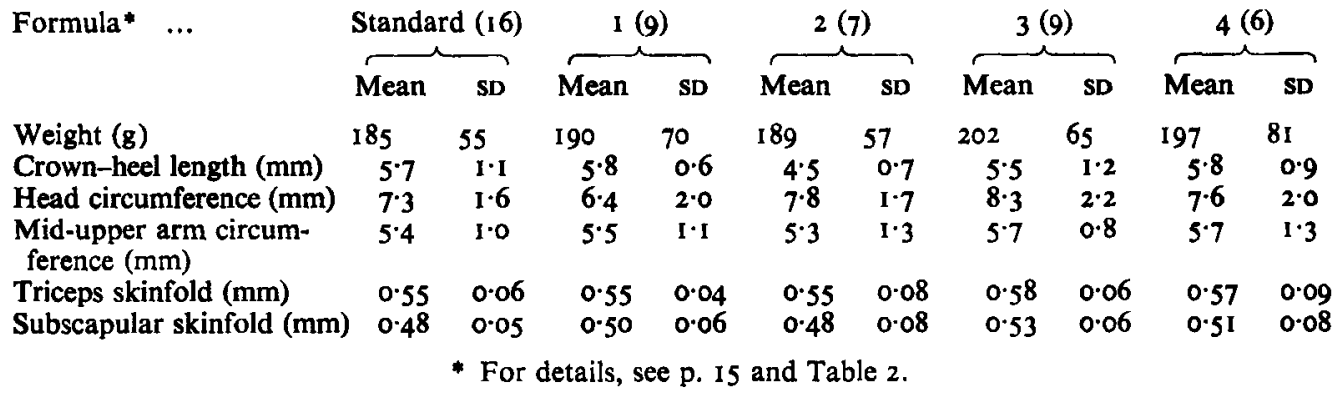

Table 6. Fasting and postprandial metabolic rate during the various balance periods (postprandial MR calculated from area under curve of five measurements during the first postprandial hour)*

(Mean values and standard deviations; no. of infants in parentheses)

\begin{tabular}{|c|c|c|c|c|}
\hline \multirow[b]{2}{*}{ Formula } & \multicolumn{2}{|c|}{$\begin{array}{c}\text { Fasting MR } \\
\text { (kJ/kg per d) }\end{array}$} & \multicolumn{2}{|c|}{$\begin{array}{c}\text { Postprandial MR } \\
\text { (kJ/kg per d) }\end{array}$} \\
\hline & Mean & SD & Mean & SD \\
\hline Standard (16) & 249 & 36 & 282 & 64 \\
\hline (9) & 255 & 32 & 296 & 72 \\
\hline (7) & 254 & 40 & 292 & 79 \\
\hline (9) & 268 & 44 & 314 & 58 \\
\hline (6) & 275 & 47 & 318 & 70 \\
\hline
\end{tabular}

Table 7. Plasma osmolality and blood gas results on the various formulas

(Mean values and standard deviations)

\begin{tabular}{|c|c|c|c|c|c|}
\hline \multirow{2}{*}{ Formula } & \multicolumn{2}{|c|}{$\begin{array}{l}\text { Plasma osmolality } \\
(\mathrm{mOsm} / \mathrm{kg})\end{array}$} & \multicolumn{2}{|c|}{ Capillary blood pH } & \multirow{2}{*}{$\begin{array}{c}\text { Mean } \\
\text { capillary blood } \\
\text { base excess }\end{array}$} \\
\hline & Mean & SD & Mean & sD & \\
\hline Standard & 293 & 12 & $7 \cdot 31$ & 0.08 & -3 \\
\hline 1 & $29 I$ & 14 & $7 \cdot 32$ & 0.09 & -4 \\
\hline 2 & 296 & 10 & $7 \cdot 26$ & 0.07 & -8 \\
\hline 3 & 301 & 10 & $7 \cdot 26$ & 0.07 & -3 \\
\hline 4 & 305 & 12 & $7 \cdot 22$ & 0.06 & -10 \\
\hline
\end{tabular}

Metabolic rate

Metabolic rate results are given in Table 6. They were compared by analysis of variance. There was a trend towards higher resting metabolism as the energy content of the diet was increased, but the difference between fasting MR on standard formula and the other formulas did not reach statistical significance. Postprandial metabolism was significantly greater on formula $3(P<0.01)$ and on formula $4(P<0.001)$ than on the standard formula.

\section{Other measurements}

Table 7 shows the plasma osmolality and blood gas results. The differences in plasma osmolality on the various formulas were not significant, but when the results for the infants 
on formulas 3 and 4 were combined, the osmolality was significantly higher than when they were on the standard formula $(P<0.01)$.

There was no significant difference between the blood $\mathrm{pH}$ values of any of the formulas, though the means were lower on the formulas containing MCT.

There was in general no serious intolerance of the high-energy formulas, but regurgitations increased on formulas 3 and 4 , and one infant was withdrawn because of vomiting and diarrhoea on formula 4 . Results from this infant have not been included.

\section{DISCUSSION}

Previous high-energy feeds for immature infants have generally been in the form of concentrated formulas (Combes \& Pratt, I96I; Snyderman \& Holt, 196I; Keitel \& Chu, 1965). These provide relatively high intakes of protein and minerals, with the risk of hypernatraemia and hyperosmolality.

Since preterm babies fed mature human breast milk containing only 6-8\% protein energy (and a relatively scanty mineral content) gain weight reasonably well (Stevens, 1970), it is possible that the $12 \%$ or so of protein energy in the average low-solute cow's milk formula is unnecessarily high, even for low-birth-weight infants. Growth of immature infants is closely correlated with energy retention (Brooke et al. I979), so increasing the energy intake should result in faster growth, provided the protein concentration of the diet does not fall below an acceptable minimum and that the balance of essential amino acids is satisfactory (as it appears to be in most modern formulas).

Increasing the dietary energy density with fat or small amounts of carbohydrate is an attractive proposition since it avoids the likelihood of plasma hyperosmolality, while allowing a reasonable energy intake in an acceptable volume of feed. Such formulas are commercially manufactured for premature infants in Germany and are in widespread use, though without much evidence that they are superior to conventional formulas. However it has been shown (Wenner, 1977) that one such formula, Milupa Meb, produced more rapid weight gain in a group of preterm infants than banked expressed breast milk, and older infants (aged 3-15 months) suffering from malnutrition have been successfully rehabilitated on very-high-fat diets providing approximately $10 \%$ protein energy and producing extremely rapid growth rates (Brooke \& Wheeler, I976).

The possible drawbacks of this approach are that the increased dietary energy may not be adequately digested or absorbed; or that, having been absorbed, it may be inadequately utilized (e.g. stored as excess fat) or may generate an increased rate of resting metabolism, which would be merely wasteful.

The question of the absorption of high-energy formulas is relatively easily answered. Morales et al. (1950) showed many years ago that high fat intakes resulted in more steatorrhoea in preterm infants, but in greater net fat absorption. The studies reported here confirm their findings. On all the high-energy formulas faecal energy increased, proportion of energy absorption declined, but total net digestible energy rose.

There was no particular advantage in the use of MCT in these studies, though the replacement of other dietary fats by MCT has previously been found to reduce steatorrhoea in preterm infants (Tantibhedhyangkul \& Hashim, 1971), presumably because they are, in the main, absorbed directly into the portal circulation (Holt, 1967) thus bypassing the inefficient digestive mechanisms of the immature. Perhaps the beneficial effect is impaired when high fat intakes are given. The potentially undesirable ketogenic effect of MCT (Schon et al. 1959) was probably the cause of the metabolic acidosis in the infants fed on the MCT formulas.

The problem of the disposal of the absorbed energy is more difficult. If the infants 
promptly grew faster, one could readily recommend the use of this type of feeding where volume tolerance was poor. However, the infants did not grow faster, or not much faster, during the relatively short periods of study. This has to be explained, since they retained more food energy on the high-energy formulas. Two possible explanations spring to mind. One is that growth was masked by reduction in body water following a relative reduction in carbohydrate intake on the high-energy formulas. This does not seem very likely, since there was little reduction in carbohydrate energy on formulas 3 and 4 , and since there was no rebound weight gain on reverting to the standard formula. The other explanation could be that the high-energy formulas stimulated increased energy expenditure. There is evidence that unbalanced feeding of high fat diets to rats results in decreased weight gain in spite of greater over-all energy intake, because of an increase in resting metabolism (Gurr et al. 1979), presumably due to rapid oxidation of the fats. It is likely that this phenomenon also occurs in low-birth-weight infants, since the infants described in the present study had higher rates of postprandial (and probably also of fasting) metabolism while on the high-energy formulas, although the differences did not account for all the additional retained energy. However, the practical limitations of measuring oxygen consumption over long enough periods in infants limit the usefulness of the results. It is possible that over $24 \mathrm{~h}$ the increased metabolic rate could account for a significant proportion of the additional retained energy, if it could be properly measured. Improved techniques of energy expenditure measurement, such as gradient layer calorimetry, would be necessary to prove this point.

From the results of these studies, the use of fat supplements, though increasing net digestible energy, cannot be particularly recommended, due to their failure to stimulate growth, and it is unlikely that sick infants or infants intolerant of normal feed volumes would be able to utilize the fat any more efficiently. However, the possibility that a useful increase in growth might result from longer periods of feeding with similar formulas is at the moment under investigation.

Martin Bland and Patricia Bailey (statisticians in the Department of Clinical Epidemiology, St George's Hospital Medical School) gave invaluable help with the statistical analyses. 
A P PENDIX

Energy balance in sixteen low-birth-weight infants on a low-solute cow's-milk-based infant formula $(\mathrm{kJ} / \mathrm{kg}$ per $d)$

(Mean values and standard deviations)

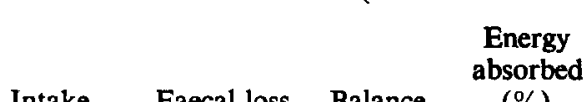

Intake Faecal loss Balance $(\%)$

PA

$\begin{array}{lrl}511 & 204 & 307 \\ 509 & 143 & 366 \\ 514 & 268 & 245 \\ 501 & 143 & 358 \\ 517 & 167 & 350 \\ 508 & 253 & 255 \\ 509 & 99 & 410 \\ 508 & 189 & 319 \\ 508 & 179 & 329 \\ 517 & 266 & 251\end{array}$

Mean \pm SD $510 \pm 5$

$319 \pm 55$
JR

520
520
518
519
519
521
534
572
572
561
Mean \pm SD $536 \pm 23$

$\begin{array}{lll}232 & 288 & 55 \\ 129 & 391 & 75 \\ 177 & 341 & 66 \\ 116 & 403 & 78 \\ 184 & 335 & 65 \\ 241 & 280 & 54 \\ 137 & 397 & 74 \\ 178 & 394 & 69 \\ 186 & 386 & 67 \\ 150 & 410 & 73\end{array}$

I $73 \pm 4 I \quad 363 \pm 48$

AL

\begin{tabular}{|c|c|c|}
\hline $60 I$ & 3I I & 290 \\
\hline 610 & 310 & 310 \\
\hline 609 & 289 & 320 \\
\hline 609 & 278 & 331 \\
\hline 600 & 277 & 322 \\
\hline 605 & 213 & 392 \\
\hline 588 & 273 & 315 \\
\hline 592 & 274 & 318 \\
\hline 595 & 275 & 320 \\
\hline 594 & 294 & 300 \\
\hline \multirow[t]{2}{*}{ Mean \pm SD $600 \pm 8$} & $279 \pm 26$ & $322 \pm 27$ \\
\hline & \multicolumn{2}{|l|}{ LL } \\
\hline 495 & 167 & 328 \\
\hline 510 & 135 & 375 \\
\hline 521 & I I I & 410 \\
\hline 519 & 109 & 402 \\
\hline 518 & 132 & 386 \\
\hline 520 & 99 & $42 I$ \\
\hline 520 & 108 & 412 \\
\hline $53 I$ & 136 & 395 \\
\hline 528 & 109 & 419 \\
\hline 530 & 103 & 427 \\
\hline
\end{tabular}

Mean \pm SD $519 \pm$ I I
Intake

Faecal loss Balance

Energy

absorbed

JK

521
518
519
508
519
519
520
521
520
$518+4$

$\begin{array}{rll}250 & 270 & 52 \\ 153 & 365 & 70 \\ 215 & 304 & 59 \\ 106 & 402 & 79 \\ 224 & 295 & 57 \\ 126 & 393 & 76 \\ 183 & 337 & 65 \\ 104 & 417 & 80 \\ 89 & 431 & 83\end{array}$

$16 \mathrm{I} \pm 59$

$357 \pm 58$

$69 \pm$ II

PF

$\begin{array}{rll}192 & 361 & 65 \\ 157 & 394 & 72 \\ 127 & 427 & 77 \\ 157 & 403 & 72 \\ 97 & 435 & 82 \\ 180 & 380 & 68 \\ 110 & 452 & 80 \\ 165 & 400 & 71 \\ 165 & 395 & 71 \\ 145 & 410 & 74\end{array}$

$150 \pm 30 \quad 406 \pm 27 \quad 73 \pm 5$

AS

$\begin{array}{lll}258 & 310 & 55 \\ 234 & 335 & 59 \\ 211 & 358 & 63 \\ 173 & 392 & 69 \\ 207 & 364 & 64 \\ 179 & 381 & 68 \\ 230 & 330 & 59 \\ 191 & 375 & 66 \\ 212 & 360 & 63 \\ 200 & 371 & 65\end{array}$

$210 \pm 26 \quad 358 \pm 25 \quad 63 \pm 4$

SW

$\begin{array}{lll}218 & 387 & 64 \\ 217 & 395 & 65 \\ 193 & 420 & 69 \\ 184 & 425 & 70 \\ 185 & 436 & 70 \\ 197 & 421 & 68 \\ 219 & 400 & 65 \\ 175 & 455 & 72 \\ 167 & 461 & 73 \\ 195 \pm 19 & 422 \pm 26 & 68 \pm 3\end{array}$




\section{Appendix-continued}

(Mean values and standard deviations)

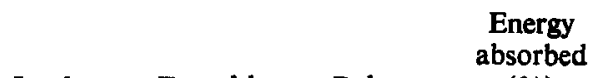

Intake Faecal loss Balance (\%) JW

$\begin{array}{llll}\mathbf{6 2 3} & 391 & \mathbf{2 3 2} & \mathbf{3 7} \\ \mathbf{6 0 2} & \mathbf{2 2 0} & 382 & 63 \\ \mathbf{5 9 5} & \mathbf{4 2 2} & 173 & \mathbf{2 9} \\ \mathbf{6 0 4} & \mathbf{2 2 8} & \mathbf{3 7 6} & \mathbf{6 2} \\ \mathbf{5 9 7} & \mathbf{2 2 7} & 370 & \mathbf{6 2} \\ \mathbf{6 0 3} & 293 & 310 & \mathbf{5 1} \\ \mathbf{6 0 2} & \mathbf{2 9 6} & 304 & \mathbf{5 0}\end{array}$

Mean \pm SD $604 \pm 9$ $297 \pm 82$

\section{Intake}

Energy absorbed

Faecal loss Balance

$$
\text { LF }
$$

$\begin{array}{rll}216 & 306 & 59 \\ 105 & 416 & 80 \\ 99 & 422 & 81 \\ 118 & 395 & 77 \\ 142 & 383 & 73 \\ 139 & 386 & 74 \\ 176 & 338 & 66 \\ 120 & 402 & 77 \\ 116 & 401 & 78\end{array}$

Mean \pm SD $520 \pm 4$

JS

$\begin{array}{lrll}\mathbf{6 2 2} & \text { III } & 511 & \mathbf{8 2} \\ \mathbf{6 3 6} & \mathbf{1 4 8} & \mathbf{4 8 8} & \mathbf{7 7} \\ \mathbf{6 2 9} & 112 & \mathbf{5 1 7} & \mathbf{8 2} \\ \mathbf{6 5 9} & 172 & \mathbf{4 8 6} & \mathbf{7 4} \\ \mathbf{6 2 9} & \mathbf{1 1 3} & \mathbf{5 1 6} & \mathbf{8 2} \\ \mathbf{6 4 4} & 97 & 547 & 85 \\ \mathbf{6 2 2} & 171 & \mathbf{4 5 1} & \mathbf{7 3} \\ \mathbf{6 2 2} & 168 & \mathbf{4 5 4} & 73 \\ \mathbf{6 2 7} & 145 & \mathbf{4 8 2} & \mathbf{7 7} \\ \mathbf{6 2 5} & 101 & \mathbf{5 2 4} & \mathbf{8 4} \\ \mathbf{6 2 7} & 162 & 465 & 74\end{array}$

Mean \pm SD $631 \pm I I \quad 136 \pm 30 \quad 495 \pm 31 \quad 78 \pm 5$

\section{MI}

$\begin{array}{llr}513 & 170 & 343 \\ 516 & 450 & 66 \\ 513 & 222 & 291 \\ 496 & 170 & 326 \\ 449 & 280 & 169 \\ 506 & 341 & 165 \\ 507 & 137 & 370 \\ 508 & 369 & 139 \\ 516 & 197 & 319 \\ 519 & 291 & 228\end{array}$

Mean \pm SD 504 \pm 21 $263 \pm$ I0I $242 \pm 103$

$\begin{array}{lc}67 & 443 \\ 13 & 425 \\ 57 & 477 \\ 66 & 479 \\ 38 & 494 \\ 33 & 492 \\ 73 & 509 \\ 27 & 512 \\ 62 & 515 \\ 44 \quad \text { Mean } \pm \text { SD } 482 \pm 31 \\ 48 \pm 20\end{array}$

\section{PM}

$\begin{array}{cl}548 & 349 \\ 561 & 161 \\ 566 & 206 \\ 560 & 184 \\ 562 & 207 \\ 564 & 189 \\ 565 & 248 \\ 563 & 180 \\ 566 & 218 \\ 574 & 205 \\ 571 & 156 \\ \text { Mean } \pm \text { SD 564 } \pm 7 & 209 \pm 53\end{array}$

$\begin{array}{ll}198 & 36 \\ 400 & 71 \\ 360 & 64 \\ 376 & 67 \\ 355 & 63 \\ 375 & 66 \\ 317 & 56 \\ 383 & 68 \\ 348 & 61 \\ 369 & 64 \\ 415 & 73 \\ 354 \pm 58 & 63 \pm 10\end{array}$
$137 \pm 38$

$383 \pm 38$

FB

$\begin{array}{rll}154 & 381 & 7 \mathrm{r} \\ 268 & 272 & 50 \\ 92 & 444 & 83 \\ 207 & 430 & 68 \\ 226 & 338 & 60 \\ 232 & 341 & 60 \\ 148 & 417 & 74 \\ 113 & 441 & 80 \\ 397 & 175 & 31 \\ 204 \pm 93 & 360 \pm 90 & 64 \pm 16\end{array}$

\section{HA}

$\begin{array}{rll}200 & 243 & 55 \\ 200 & 225 & 53 \\ 124 & 353 & 74 \\ 95 & 384 & 80 \\ 152 & 342 & 69 \\ 32 & 460 & 93 \\ 228 & 281 & 55 \\ 185 & 327 & 64 \\ 114 & 401 & 78 \\ 142 \pm 62 & 335 \pm 76 & 69 \pm 14\end{array}$

\section{MH}

$\begin{array}{lll}108 & 463 & 81 \\ 97 & 484 & 83 \\ 152 & 446 & 75 \\ 125 & 486 & 80 \\ 217 & 350 & 62 \\ 226 & 350 & 61 \\ 156 & 413 & 73 \\ 251 & 313 & 55 \\ 407 & 457 & 81 \\ 214 & 358 & 63 \\ 236 & 333 & 58 \\ 216 & 354 & 62 \\ 193 & 379 & 66 \\ 248 & 329 & 57 \\ 203 \pm 78 & 373 \pm 86 & 68 \pm 10\end{array}$




\section{REFERENCES}

Brooke, O. G. \& Alvear, J. (1976). Nutr, Metab. 20, 165.

Brooke, O. G., Alvear, J. \& Arnold, M. (1979). Pediat. Res, 13, 215.

Brooke, O. G. \& Wheeler, E. F. (1976). Arch. Dis. Child. 51, 968.

Combes, M. A. \& Pratt, E. L. (1961). Am. J. Dis. Child. ro2, 610.

Committee on Nutrition: Parenteral feeding (1972). Pediatrics, Springfield 49, 776.

Falkner, F., Steigman, A. J. \& Cruise, M. O. (1962). J. Pediat. 60, 895.

Fomon, S. J., Ziegler, E. E. \& Vásquez, H. D. (1977). Am. J. Dis. Child. r3r, 463.

Gregory, G. A. (1972). Pediat. Clin. N. Am. 19, 31 I.

Gurr, M. I., Rothwell, N. J. \& Stock, M. J. (1979). Proc. Nutr. Soc. 38, 6A.

Hardy, J. B. \& Goldstein, E. O. (195 I). J. Pediat. 34, 154.

Holt, P. R. (1967). Gastroenterology 53, 961.

Keitel, H. G., Bachman, B. \& Smith, I. (1965). Pediat. Clin. N. Am. 12, 337.

Keitel, H. G. \& Chu, E. (1965). Pediat. Clin. N. Am. 12, 309.

Miller, D. S. \& Payne, P. R. (1965). Br. J. Nutr. r3, 501.

Morales, S., Chung, A. W., Lewis, J. M., Messina, A. \& Holt, L. E. (1950), Pediatrics, Springfield 6, 86.

Postuma, R. \& Trevenen, C. L. (1979). Pediatrics, Springfield 63, I 10.

Schon, H., Lippach, I. \& Gelpke, W. (1959). Gastroenterologia 9r, 199.

Snyderman, S. E. \& Holt, L. E. (1961). Pediatrics, Springfield 58, 237.

Stevens, L. H. (1970). Aust. Paediat. J. 6, 70.

Tantibhedhyangkul, P. \& Hashim, S. A. (197I). Bull. N.Y. Acad. Med. 47, 491.

Wenner, U. (1977). Fortschr. Med. 95, 441. 